\title{
"Que nadie duerma" de Juan José Millás: la construcción de un personaje femenino
}

\section{"Que nadie duerma" by Juan José Millás: The construction of a female character}

\author{
Carmen Fragero Guerra \\ Universidad de Córdoba, España \\ sc2frguc@uco.es
}

Resumen: En este artículo analizamos el modo en el que Juan José Millás (I946) construye a la protagonista de su novela Que nadie duerma (2018). Para esto, I) explicamos en qué consiste el estado mental de la limerencia y por qué Lucía es una protagonista limerente. 2) Igualmente ligamos la construcción de la protagonista por parte del autor a la teoría de la hiperculturalidad del filósofo surcoreano Byung-Chul Han (I959). 3) Además, desde una perspectiva más literaria, consideramos el modo narrativo de Que nadie duerma.

Concluimos que esta narración muestra la evasión de una mujer abrumada por las turbulencias socioeconómicas del siglo XXI- en un universo imaginario y antirreal. Pero esta obra literaria es, sobre todo, un objeto estético en el que se descubren complejas conexiones internas entre el modo narrativo, el vocabulario, la trama y el significado.

Palabras clave: literatura contemporánea, novela, personaje femenino, Juan José Millás, Que nadie duerma.

Abstract: In this article we analyse how Juan José Millás (1946) builds the female protagonist of his novel Que nadie duerma (2018). We explain $I$ ) the meaning of limerence, and why Lucía is a limerent protag- 
onist. 2) We also link the author's construction of the protagonist to the theory of hyperculturality formulated by the South Korean philosopher Byung-Chul Han (1959). 3) In addition, we consider the narrative mode of Que nadie duerma.

We conclude that this narrative shows the evasion of a woman overwhelmed by the socioeconomic turbulences of the $21^{\text {st }}$ century- in an imaginary and antirealistic universe. But this literary work is, above all, an aesthetic object, because complex internal connections are discovered among its narrative mode, vocabulary, plot and meaning.

Keywords: Modern literature, novel, female character, Juan José Millás, Que nadie duerma.

Recibido: 3 I de enero de 202 I Aceptado: 24 de agosto de $202 \mathrm{I}$ https://dx.doi.org/IO.I 5 I 74/rv.vi 4i29.605

\title{
Introducción
}

\begin{abstract}
A nalizamos Que nadie duerma (2018) de Juan José Millás con Ael objetivo de contribuir a aislar las claves de la novela contemporánea española; pues solo desde la profundización en obras particulares se logrará, en un futuro, una visión de conjunto del género novelístico escrito en español, favorecida, además, por la perspectiva temporal.

Según Toni Dorca, Millás pertenece a un grupo de escritores -entre los que se encuentran José María Merino, Marina Mayoral, Antonio Muñoz Molina y Javier Marías- ya asentados en el campo literario en la década de los ochenta, y que han convivido con otros más veteranos -como Camilo José Cela, Gonzalo Torrente Ballester, Miguel Delibes, Carmen Martín Gaite, Juan Benet o
\end{abstract}


Juan Goytisolo-, "convivencia" que desembocó en una "situación de libertad y heterogeneidad" en el panorama de la narrativa hispánica (Dorca, 1997: 309).

Alicia Montejo, afinando más, considera que la narrativa española de los últimos 30 ańos se caracteriza por el "individualismo" y la "desmitificación de sistemas culturales y morales precedentes", así como por la importancia concedida a la historia novelesca frente al experimentalismo anterior; todo lo cual implica una "remodelación del canon" (Montejo, 2010: s. p.). Asimismo, añade que frecuentemente los personajes encarnan a seres que buscan su entidad personal. La estructura de la trama de estas novelas es lineal y se desarrolla en un espacio urbano; características que observamos en Que nadie duerma de Millás. Igualmente, Montejo señala a otros novelistas contemporáneos a Millás -como Eduardo Mendoza, Álvaro Pombo, Soledad Puértolas, Almudena Grandes, Javier Marías y Javier Cercas, entre otros-, que suelen compartir estos rasgos (Montejo, 2010: s. p.).

Las tres primeras obras de Millás, Cerbero son las sombras (1975), Visión del ahogado (1977) y Eljardin vacio (1981), son consideradas por Luigi Contadini "novelas de transición” porque su cronología coincide con la transición política (muerte de Franco, elecciones e intento de golpe de estado el 23 de febrero de 1981) (Contadini, 2013: 32). Estas se caracterizan por "el extravío de las identidades, la imposibilidad de reconocerse en lo que ha ocurrido, la dificultad de comunicar y la presencia de espacios angostos y de vacíos ahogantes", aspectos que repercuten en el modo narratológico y en la consideración del tiempo (Contadini, 2013: 34).

A las obras anteriores las siguen Papel mojado (1983), Letra muerta (1984), Tonto, muerto, bastardo e invisible (1995), Trilogía de la soledad (1996) -que contiene El desorden de tu nombre (1987), La soledad era esto (1990), Premio Nadal, y Volver a casa (1990)-, El orden alfabético (1998) y No mires debajo de la cama (1999). 
En el siglo xxI, Millás continúa escribiendo Dos mujeres en Praga (2002) -Premio Primavera-, La ciudad (2005), Laura y Julio (2006), El mundo (2007) -su autobiografía, Premio Planeta y Premio Nacional de Narrativa-, Lo que sé de los hombrecillos (2010), La mujer loca (2014), Desde la sombra (2016), Mi verdadera historia (2017) y su reciente novela, Que nadie duerma (2018).

Concretamente, en Que nadie duerma se aprecia, entre otros aspectos, cierta influencia de los personajes de Edgar Allan Poe, porque Lucía, su protagonista, al igual que los del cuentista bostoniano, comienza siendo un personaje normal, pero su personalidad obsesiva aumentará hasta derivar en una locura total. Asimismo, la transformación de Lucía en un pájaro -y su modo de narración ambivalente- recuerda a la de la Metamorfosis (Die Verwandlung, 1915) de Franz Kafka. También, en la presentación del mundo imaginario y delirante como un continuo de la realidad -que se muestra en las fabulaciones de la protagonista de Que nadie duer$m a-$, se puede ver una influencia de Martín Gaite, conocida y admirada por Millás.

En este trabajo, nos centramos en la protagonista femenina (Lucía) de Que nadie duerma y sus problemas (provocados por crisis social); para ello tomamos de la psicología un modelo para analizar a este personaje, con lo que conferimos al objeto literario -Que nadie duerma-, una visión multidisciplinar.

Igualmente, al considerar a la protagonista de esta novela una expresión o muestra de un mundo hipercultural, transferimos la teoría social sobre la hiperculturalidad del filósofo surcoreano Byung-Chul Han (Seul, 1959) al campo literario. Y, de este modo, hacemos realidad la afirmación de Culler, según la cual "las obras que se consideran teoría producen efectos más allá de su ámbito original" (2014: 13).

La complejidad del carácter de la protagonista, Lucía, no se entiende sin exponer antes el concepto de limerencia y las causas que 
lo provocan. Con esto nos interesa resaltar la utilización por parte de Millás de modelos de conducta previamente estudiados por la psicología y psiquiatría.

$\mathrm{Al}$ interrelacionar la limerencia de la protagonista con la hiperculturalidad de la sociedad actual pretendo establecer puentes de comunicación entre lo individual y lo social. De este modo, trato de explicar el proceso mental que determina el comportamiento la protagonista.

A continuación, en primer lugar, 1) explicaré qué es la limerencia y por qué la protagonista de esta novela, Lucía, se puede considerar un sujeto limerente; asimismo, 2) analizaré a esta protagonista bajo la luz de la teoría de la hiperculturalidad, formulada por el filósofo Byung-Chul Han. Más adelante, ya desde una perspectiva estrictamente literaria, 3) estudiaré el modo narrativo del texto literario y cómo este se ajusta a su tema.

\section{1. ¿Qué es la limerencia?}

El término de limerencia (limerence en inglés) fue acuñado por la psicóloga estadounidense Dorothy Tennov (1928-2007), quien en Love and limerence: The experience of being in love (1979) enumera las características básicas que experimenta el sujeto limerente (SL) o enamorado, algunas de las cuales expongo a continuación: pensamientos intrusivos sobre la persona deseada u objeto limerente (OL); deseos de ser correspondido, y cambios positivos de humor si este cree que el oL reacciona favorablemente a sus insinuaciones, entre otros aspectos (Traducción/adaptación personal de Tennov, 1979: 23-24). ${ }^{1}$

${ }^{1}$ Otras de las características básicas que experimenta el sujeto limerente o enamorado son: incapacidad para tener otro ol mientras el sujeto limerente posea ya uno; alivio pasajero de la pasión no correspondida mediante imaginaciones, en las que el ol actúa recíprocamente; miedo a ser rechazado y, a veces, sen- 
Su campo de estudio ha sido continuado por diferentes autores. Si Tennov no consideraba la limerencia una situación mental patológica (sino una fase inicial del amor apasionado, previo al de las parejas estables), algunos de sus seguidores, como Wakin y Vo, la han relacionado con trastornos psicológicos añadidos, caracterizados por la obsesión compulsiva, sobre todo en su fase más aguda (Wakin/Vo, 2008: 2). ${ }^{2}$

\section{1. Lucía sujeto limerente}

Lucía, la protagonista de la trama de Que nadie duerma, se encuentra en el Madrid afectado por la crisis económica (comenzada en España en el año 2007). Vive sola en un apartamento, sin trabajo y sin perspectiva de encontrar otra ocupación de informática, que es campo profesional, y tiene que dedicarse a ser taxista. Un día se enamora locamente de su vecino (Braulio Botas, actor de teatro) porque oía, a través de la rejilla de ventilación de su cuarto de baño, el aria "Nessun dorma" (de la ópera Turandot de Giacomo

timiento de vergüenza ante el oL; intensificación del deseo amoroso en situaciones adversas; sensibilidad para interpretar los actos del ol como favorables; dolor físico -en la parte central del pecho- cuando existe incertidumbre sobre la situación amorosa; extremada alegría o "a feeling of walking in the air" cuando el sL vislumbra cierta correspondencia; olvido de otras preocupaciones ante la intensidad del sentimiento amoroso y, finalmente, capacidad para enfatizar las cualidades positivas del ol y no fijarse en las negativas, que las justifica (Traducción/adaptación personal de Tennov, 1979: 23-24).

${ }^{2}$ Según Carlin Flora, al sufrir pensamientos reiterados e intrusivos, el sujeto limerente pierde su capacidad de concentración, y puede dedicar hasta el 95\% de su tiempo a pensar en la persona deseada (2017: 85). Algunos expertos consideran que la limerencia debe tratarse psiquiátricamente, aunque otros difieren, arguyendo que ser adicto a una persona no es una enfermedad sino el resultado de ejercitar la capacidad de amar desmesuradamente (Earp/Wudarczyk/Foddy, 2017: 85). 
Puccini), mientras que él la escuchaba. A partir de un breve encuentro con su vecino, Lucía queda fascinada y, progresivamente, asistimos a una transformación de su personalidad (2018, 29-31).

Experimenta las sensaciones que presenta el estado de limerencia, enumeradas más arriba; la protagonista Lucía se convierte en sujeto limerente (sL). Piensa continuamente en Braulio Botas-que pasa a objeto limerente (OL)-, y todas sus acciones van encaminadas hacia despertar su agrado en un futuro encuentro; cuida su taxi (46), intenta ser más culta y vestirse de un modo más atractivo (49). ${ }^{3}$

Una de las razones de su enamoramiento es el aspecto de pájaro de Braulio, semejante al que ella creía tener, heredado de su madre (30). En esta etapa -que coincide formalmente con la primera parte de la novela- Lucía elucubra sobre Braulio e, incluso, ha comprado una licencia de taxi con la esperanza de recogerlo en alguno de sus trayectos. Pero su obsesión gradualmente se incrementa; se peina como la princesa Turandot para estar bella cuando encuentre a su amado y, asiduamente, oye y canta en su taxi, el aria del acto final de Turandot, "Nessun dorma". Fantasea con los posibles encuentros con Braulio, y su fabulación le lleva a imaginar que las calles de Madrid son las de Pekín. Por esto, cuando un cliente, Ricardo (periodista de temas de económicos) la invita a almorzar, responde: "Tendría que ser un restaurante chino (...), hoy me he levantado con la idea de que trabajaba en Pekín” (109).

También se maquilla con polvos de arroz al modo de las mujeres chinas e, incluso, se tatúa "bordeando la falda del monte de Venus" el título del aria "Nessun dorma” para sorprender a Braulio en el futuro encuentro (63). Lucía así pretende mejorar su aspecto pen-

${ }^{3}$ Incurre, pues, como señala Richard D. Chessick, en la fase inicial de este estado mental, caracterizada porque el S.L disfruta de: "More joy in life, and an enhanced sense of being alive" (1992: 360). 
sando en Braulio:4 "Siempre se vestía contando con la posibilidad de que ese día se encontrara con Braulio, Braulio Botas, por lo que también llevaba un conjunto de ropa interior bastante especial, de color calabaza, transparente y sutil como una membrana” (59).

La protagonista se aliena en un mundo fantástico, Pekín, por donde conduce imaginando que es la princesa Turandot. Esta creatividad (junto con la que derrocha en mejorar su aspecto físico) se puede achacar al estado de limerencia, pues, según Richard D. Chessick, existe una transferencia del potencial creativo de la imaginación amorosa hacia otras esferas de la vida - "transference of creativity" (1992: 360)-; es decir, las personas que sufren este tipo de enamoramiento transfieren a otros campos la creatividad, ya ejercitada en sus imaginaciones sobre el objeto limerente o deseado (1992: 364-365). Además, su pensamiento divergente produce unos comportamientos fuera de la norma. Así, Lucía no solo es original en su atuendo $(2018,59)$, sino en el modo franco y directo con que trata a sus clientes; le describe ingeniosamente a un ciego la calle y sus transeúntes (75-76); riñe a un marido que ridiculizaba el físico de su mujer en el taxi (99); hace el amor con los clientes solamente por aliviar las penas de estos -bien con un joven, que estaba triste después de una noche de fiesta en las que sus expectativas se truncaron, o con un hombre, que le confesó llorando que tenía cáncer (53-72)-.

Según Chessick, el enamorado en situaciones adversas debe utilizar sus fuerzas creativas para solucionar las tensiones internas, producidas por el ataque a su narcisismo y la pérdida del objeto limerente. Así el sujeto limerente puede llegar a soluciones cons-

${ }^{4}$ Según Albert Wakin y Duyen B. Vo, en estos primeros momentos de enamoramiento los sujetos limerentes "make constant attempts to present self (e.g., in physical appearance, behavior and attitude) most favorably to Lo" (2008: 5). 
tructivas o destructivas (1992: 370). ${ }^{5}$ La protagonista, Lucía, elegirá las segundas. Quizá, la destrucción total es la única respuesta posible a la posterior traición de Braulio, Berta y Ricardo que puede saciar su sed de venganza.

\section{1. 1. Causas de la limerencia de la protagonista}

Según Lynn Willmott y Evie Bentley, los sujetos limerentes consideran su estado como una oportunidad para afrontar experiencias negativas de su vida pasada, comenzando así un camino hacia el conocimiento de sí mismos o hacia su autenticidad (2015: 29). ${ }^{6}$ Pueden ser distintas las causas que provocaron la limerencia: depresión, muerte de un ser querido, cansancio de la pareja del momento, entre otras. Como los mismos limerentes (encuestados por Willmott y Bentley) apuntan, la limerencia está desencadenada por "storm situation" (Willmott/Bentley, 2015: 29).

En el caso de la protagonista, Lucía, la situación turbulenta o “storm situation" que provoca su limerencia está apuntalada en acontecimientos vividos en su infancia, contratiempos recientes, $y$ su soledad; factores que trataremos a continuación.

${ }^{5}$ Según Richard D. Chessick, "falling in love represents a creative effort to find a solution for unbearable narcissistic and libidinal tensions, often in an emergency situation of object loss or narcissistic wounding. Depending on the nature of this effort, the falling in love can be a constructive, helpful, and forward-moving event, or it can lead to destruction and tragedy" (1992: 370).

${ }^{6}$ Es decir, según Lynn Willmott y Evie Bentley "they appeared to begin a process of insight and potential self-growth" (2015: 29). 


\subsubsection{Acontecimientos vividos en su infancia}

El carácter $a$ ) obsesivo de la protagonista y b) ciertos problemas de apego en su infancia provocan su disposición hacia un estado de limerencia.

a) Desde las primeras líneas del texto encontramos a una protagonista obsesionada por su físico, que lo cree similar al de las aves. Esta obsesión aumentará en el desarrollo de la trama, y también se ramificará hacia el modo compulsivo de amar a Braulio. ${ }^{7}$ La fuerza temática (o el impulso) que el personaje principal infunde a la acción viene dada por su estado de limerencia extrema, que adquiere verosimilitud gracias a la narración focalizada por la protagonista: "Al verse en el espejo, Lucía dijo: Esa gorda soy yo. [...] Más que gorda, era una falsa delgada. Se lo había dicho su madre cuando era una cría [...] - [...] eres una falsa delgada, como la mayoría de las aves zancudas" (2018: 9).

Lucía está ligada al mundo de las aves desde que le regalaron un pájaro (Calaf) el día de su undécimo cumpleaños. Ese mismo día un mirlo gigante desencadenó casualmente la muerte de su madre -al chocar con su sien, mientras esta estaba en el jardín (16-17)-. Además, no solo sus muslos se parecían a las delgadas patas de las aves, sino que poseía una nariz aguileña como estas, características que compartía con su madre.

b) Pero, la limerencia también puede estar asociada a problemas de apego en el seno familiar durante la infancia, según Willmott y Bentley (2015: 21). ${ }^{8}$ Así, la ansiedad que Lucía sufrió en su infan-

${ }^{7}$ Según Carlin Flora, "those whose love is unrequited, remain in limerence [...] it is a combination of obsessive compulsive disorder and addition (to another person)" (2017: 85).

8 "Limerence may also be associated with attachment disorders [...] with the potential role of early caregiver attachments highlighted regarding some positive, but mostly negative experiences"(Willmott/ Bentley, 2015: 21) 
cia por la muerte de su madre se reproduciría en su modo de amar obsesivo. Por esta razón siente especial ternura hacia Braulio, al que imagina solo en este mundo porque había perdido a su madre al igual que ella (2018: 64).

\subsubsection{Contratiempo reciente: pérdida de su trabajo}

La crisis económica, sufrida en España al final de la primera década del dos mil, generó numerosas calamidades; entre ellas, el afloramiento de problemas mentales en aquellas personas que perdieron su empleo. Algunas de estas, ordenadas por la rutina de su trabajo, aparentaban una normalidad psíquica. Pero la nueva situación las llevó al desequilibrio total o a buscar mundos ficticios que sustituyeran su desolada realidad como, por ejemplo, hizo (en la trama de Que nadie duerma) el taxista que recoge a Lucía, que "también [era] un informático que al quebrar su empresa no había logrado recolocarse en el sector" (11), y del que Lucía tomó la idea de comprar un taxi, y de alternar imaginariamente las ciudades por las que conducía: "[Él] cada día [...] [imaginaba] que [...] [trabajaba] en una ciudad distinta. En Nueva York, en Delhi, en México” (11).

Por estar sin trabajo, Lucía pierde su autoestima, lo que aumenta su sensibilidad - "lloraba como una idiota al oír la opera de Turandot de Puccini” (20)-, con lo que se convierte en un sujeto que necesita amor, aunque este sea imaginado. En el siguiente párrafo que transcribimos (del final del capítulo primero) se dibujan las claves -la muerte de su compañera, recuerdo de su madre, obsesión por las aves y la pérdida de empleo por culpa de la corrupción-que perfilarán el carácter de Lucía y determinarán su acción posterior:

Justo en el momento en el que el ataúd descendía hacía la tumba, un pájaro grande aleteó sobre las cabezas de los deudos y Lucía cayó 
en la cuenta de que al día siguiente cumpliría los años que tenía su madre cuando murió. Recibiría como regalo inverso la noticia de que su empresa cerraba víctima de una quiebra fraudulenta provocada por su dueño, que resultó ser un delincuente (20).

\subsubsection{La soledad}

La protagonista Lucía, además de estar sola porque carece de parientes, vive en una casa donde habitan turistas o personas de paso (con esto se dibuja el panorama de las grandes ciudades del siglo XXI en un ambiente neoliberal) (21). Cuando se encuentra con sus antiguos compañeros de trabajo, estos se mofan y extrañan de su aspecto chinesco. Asimismo, con los otros taxistas "socializar [era un] asunto que de momento no le interesaba" (47). Lucía disfruta de su soledad porque así puede dar rienda suelta a "su imaginación fantástica" (23). E, incluso, antes de haber conocido a Braulio Botas ya "hacía viajes de quinientos o seiscientos kilómetros por el mero placer de pasar seis o siete horas a solas consigo misma, dándole vueltas a esto o a lo otro" (22). Imaginaciones, pues, intrusivas y recurrentes que aumentarán progresivamente hasta conducirla al desastre (el considerarse un ave y asesinar por venganza).

También este sentimiento de soledad le predispone a estar deseosa de amar y ser correspondida, con lo que incurre en un estado propicio a la limerencia:" "Se moría literalmente de amor, no sabía de amor a quién, en todo caso a alguien de otra dimensión, como si la música auténtica perteneciera a una instancia diferente de la realidad en la que ella vivía y se colocara en la suya a través de los tabiques que separaban esas dimensiones" (2018: 28).

${ }^{9}$ Así, según Richard D. Chessik: "Before limerence begins a person may be in a state of readiness and heightened susceptibility to it, caused by [...] Psychological factors such as preceding loneliness, discontent, and alienation" (1992: 352). 
En su primer encuentro, Braulio aparece ya con características de pájaro, semejantes a las de ella (y a su madre):

La puerta se abrió un poco y una cabeza de hombre pájaro se asomó a través de la rendija resultante. Su expresión era neutra, ni de fastidio ni de alegría. De unos cuarenta y cinco ańos, alto y delgado, tenía la nariz en forma de pico de águila y el pelo, blanco exageradamente desordenado, como si se lo mesara sin pausa (30).

La comparación de su físico con el de las aves continuará cuando lo vea por segunda vez: "Los ojos de ambos se encontraron durante una eternidad fugaz y enseguida aquel rostro de pájaro se volvió de nuevo hacia su interlocutor sin dar muestras de haberla conocido" (65-66).

Aunque Lucía se siente sola, la intimidad producida en el interior de su taxi la mueve a confiar su vida e historia de amor a una clienta, Berta, que con el tiempo simulará ser su amiga. Esta mantenía relación con el mundo del teatro (conocía a Braulio Botas), por lo que escucha entusiasmada los episodios de la vida de la taxista (la muerte de su madre, su fantasiosa transformación en la princesa Turandot y la esperanza de encontrar a Braulio). Pero, Berta se aprovecha y utiliza su historia para que un amigo suyo, autor y director teatral (Santiago Cáceres, que se dio falsamente a conocer a Lucía como un periodista llamado Ricardo), la transforme en el argumento de una obra de teatro, cuyo actor principal será el mismo Braulio (191).

\section{Lucía, personaje hipercultural}

El filósofo Byung-Chul Han explica su teoría sobre la hiperculturalidad a lo largo de su libro homónimo -y más concretamente en el apartado "Hipertexto e hipercultura" (2018a: 19-28)-. La 
hiperculturalidad parte del concepto de hipertexto acuñado por Ted H. Nelson (apud. Han, 2018a: 19) pero la teoría de Han va más allá, pues, para él, la cultura actual (hipercultura) no es solo un universo de ideas entretejidas, sino que además:

a) No posee un fin determinado: "Ninguna historia, teología o teleología, la deja aparecer [a la cultura] como una unidad con sentido y homogénea" (Hans, 2018a: 21).

b) No está ligada a un lugar físico ni a lazos biológicos: "Los límites o fronteras, cuya forma está determinada por una autenticidad u originalidad cultural, se disuelven. [...] Se abre paso hacia una hiperculturalidad" (Han, 2018a: 21). Asimismo, "La cultura es desnaturalizada y liberada tanto de la 'sangre' como del 'suelo', es decir, de los códigos biológicos y de la tierra (terran) [...] Si el lugar constituye la facticidad de una cultura, la hiperculturización significa entonces su desfactifización" (Hans, 2018a: 22; comillas y cursivas en el original).

Surge, pues, "la hipercultura sin centro, sin Dios y sin lugar" (Han, 2018a: 23).

c) Se densifica, debido a la globalización impuesta por las nuevas tecnologías. Así, culturas de distintos lugares y periodos de tiempo se yuxtaponen. Es decir, los "contenidos culturales", aunque sean distintos, "se amontonan" y "se superponen y atraviesan" (Han, 2018a: 22).

A continuación, mostraré cómo la protagonista Lucía participa de las características expuestas más arriba, que son propias de la sociedad hipercultural (las refiero con las mismas letras que he usado anteriormente).

a) Lucía algunas veces conduce sin ningún fin concreto, sin sentido; incluso la elección del mapa por la que se tiene que guiarse -el de Madrid o Pekín- es caprichosa (96). También arbitrariamente dedica más tiempo a algunos clientes que a otros. 
b) Es una protagonista liberada de los lazos de la "sangre" y "del suelo" (Han, 2018a: 22). Lucía carece de familia y vive en un edificio en el que no conoce a nadie; y hasta su piso no guarda ninguna relación con el que compartió con su padre; su único "suelo" podría ser la "burbuja" de su taxi (Millas, 2018: 37).

c) Vive o imagina distintos escenarios (Pekín o Madrid) y épocas (el Madrid actual y el Pekín remoto), y los yuxtapone y aproxima en el tiempo -hasta el colmo de identificarse con la princesa china, Turandot-. Este modo de actuar es propio del ambiente hipercultural donde las culturas que se yuxtaponen pueden ser lejanas en el tiempo e, incluso, en el espacio (Han, 2018a: 22). Además ¿qué más superposición de culturas que la legendaria princesa Turandot (en el texto Lucía) se tatúe en su sexo "Nessun dorma"? (Millas, 2018: 83).

Las nuevas tecnologías evidentemente están presentes en la trama; Lucía teme que el móvil de su antiguo jefe delate su recorrido en su taxi el día que lo abandonó borracho en un descampado, donde luego murió (88); igualmente utiliza la red para obtener o buscar información, unas veces banal y otras relevante -como aquella sobre una mujer pájaro, que nació en el pasado siglo (78)-.

Pero estos detalles solo muestran una protagonista que vive en una sociedad en la que, según Han, "la comunicación digital [...] interconecta y al mismo tiempo [...] aísla” (2018b: 119). Lucía, en efecto, está aislada en su mundo. Por eso al enamorase busca en "una cercanía vecinal", alguien que la escuche (2018b: 119). Ella necesita romper las ataduras del neoliberalismo donde está mal visto "la sociabilidad de su sufrimiento" (2018b: 120); no soporta, pues, privatizar o individualizar sus angustias y, por eso, comparte su historia de amor con Berta. Pero no encuentra en esta un "oyente hospitalario", sino una traidora (2018b: 119), que se beneficia de ella, la utiliza y explota; por esto, como también sugiere Han, Berta no experimenta a Lucía "como enigma o como misterio" 
(2018b: 109); por el contrario, su pretendida amiga provoca una situación en la que "el otro [Lucía en este caso] queda sometido por completo a la teleología del provecho, del cálculo económico y de la valoración" (2018b: 109), como reza la ideología neoliberal.

Aunque Lucía esté atrapada en este mundo hipercultural, tampoco posee para liberarse lo que representa su contrario (amor a Dios, al lugar de origen, o un fin en su trayectoria vital). Ya solo le queda un mundo denso de nódulos superpuestos que crecen descontroladamente; Lucía no cree en un Dios que haga justica, solo creen ella misma, lo que le inducirá a 'tomarse la justicia por su mano'.

Podemos concluir que la hiperculturalidad que afecta al mundo actual también configura la personalidad de Lucía. Y la pregunta que el mismo Han se hace ante este modo de expansión cultural - ¿Seguirán teniendo razón aquellas 'voces ancestrales' que profetizan una desgracia [ante la hiperculturalidad]?” (Han, 2018b: 23) - puede responderse por medio del atroz desenlace de la trama de Que nadie duerma; Lucía se venga matando a Braulio, Roberta y Ricardo y, luego, se suicida tirándose por una ventana.

En la trama de esta novela el ambiente hipercultural descreído, desenraizado y desteleologizado produce una protagonista que, evidentemente, participa de estas características de su época. Pero Lucía se resiste a aceptar esta realidad. Busca, como se anhela una tabla de salvación, una oyente hospitalaria (Berta), un amante (Braulio) y un mundo (la legendaria China) que la rediman de un presente (en el que se encuentra sin empleo y familia). Pero, al sentirse traicionada por los amigos en los que confió, se venga contra ese mundo hipercultural y desubicado; reafirma sus orígenes biológicos y entidad híbrida de ave y mujer, a la vez que otorga un fin concreto, real y atroz a "su historia” personal: la venganza. Lucía presenta así resistencia al proceso de hiperculturación porque se 
siente defraudada; ha sido engañada por su jefe, por su hipotético amante y por su única amiga.

El filósofo surcoreano señala que algunas personas desarrollan "el trauma de la pérdida" frente a la creciente hiperculturalidad. Y como respuesta a esta confusión tienden a la "reteologización, remitologización y renacionalización de la cultura" (Han, 2018b: 23). Por lo que respecta a Lucía, ella enfocará "su historia" hacia un fin (la venganza) y reactivará su entidad de águila (ligada a sus orígenes) y de mujer. La crueldad de una y los encantos sexuales de otra le ayudaran a consumar su venganza:

Dicho esto, [Lucía] dio un bocado tremendo en su vientre [el de Braulio] y comenzó a eviscerarlo con la habilidad con la que un buitre vaciaría el cuerpo de un ciervo. [Braulio] Botas gemía entre el placer y el horror mientras su erección crecía. Cuando la boca de la mujer llegó al hígado gracias a la eficacia del pico del águila, se corrió con el gemido de un moribundo, alcanzando su semen la altura del techo (Millás, 2018: 211).

Esa posibilidad es la única que Lucía vislumbra. Las alternativas de resistencia, a las que alude Han, no le sirven (Han, 2018b: 23); la reteologización, porque no cree en Dios; la remitologización, porque la historia de Turandot fue la causa de su ridículo; y tampoco la renacionalización, porque no tiene ningún sentimiento patrio. Pero sí le queda su identidad. Su identidad híbrida de mujer y pájaro, que habita su cuerpo y proviene de sus orígenes (de su madre). Su desafío al ambiente hipercultural es total: mata por venganza y luego se suicida.

[Lucía] Se arrojó al vacío en medio de la tormenta. Cuando apenas había volado dos metros, el cuerpo de la mujer se desprendió del cuerpo del águila, cayendo con violencia por los efectos de 
la gravedad, mientras el ave, liberada de aquel lastre, se elevaba gloriosamente hacia el lugar del que procedían los rayos (Millás, 2018: 212).

\section{Hacia un análisis literario. El modo narrativo}

Desde una perspectiva exclusivamente literaria consideramos, a continuación, a Que nadie duerma un texto literario y objeto estético, lo que se manifiesta por sus conexiones internas entre el sentido y la forma.

Según Culler, la naturaleza de los textos literarios radica en ser objetos estéticos que "se los organiza para que todas sus partes cooperen para lograr un fin" (2014: 45). Entre las "partes" del texto literario que cooperan a ese fin estético se encuentran: la relación "ficcional" con el mundo (2014: 43), la intertextualidad, la autorreflexión o metaliteratura y el modo narrativo de la obra (2014: 46-47).

Aunque en estas páginas trataremos solo el modo narrativo de Que nadie duerma, también daremos unas pinceladas sobre su intertextualidad y autorreflexión, que se podrían desarrollar en futuras investigaciones.

Respecto a la intertextualidad, como ya hemos anunciado, es patente la influencia de La metamorfosis de Kafka (1915) en Que nadie duerma, pues no solo aparece en ciertos puntos de la trama (Gregorio Samsa se transforma en un gran insecto y Lucía, en pájaro), sino en su modo narrativo, ya que la novela del praguense presenta ciertas focalizaciones de Gregorio Samsa -"se sintió", "lo notó", "vio" (Kafka, 2018: 34)-, y otras ambiguas, que se pueden adjudicar tanto al narrador como al protagonista - “`tendría [...] que ponerse a trabajar la madre?" (Kafka, 2018: 49)-; focalizaciones parecidas a las de Lucía en Que nadie duerma. Asimismo, son 
notables las similitudes de las descripciones de los torpes movimientos de los dos metamorfoseados en ambas novelas.

Respecto a la autorreflexión o metaliteratura dispersa en Que nadie duerma, se podrían considerar en otros estudios: primero, la idea del autor respecto a la confrontación de lo "real" con lo "irreal" en la composición de una obra literaria -que aparece en el texto por medio sentencias de Braulio (Millás, 2018: 209 y 210)-; segundo, la recreación del género dramático dentro del subgénero de la novela -patente en el episodio en el que Lucía acude al estreno de la obra teatral, Lo que sé de mí, en la que se describe su vida (Millás, 2018: 183-191)-.

Centrándonos en un análisis narratológico tradicional (o de corte estructuralista) de Que nadie duerma, se observa un modo de narración en tercera persona; pero ese narrador, exterior al relato y omnisciente, la mayoría de las veces, focaliza los acontecimientos por medio de la protagonista (Lucía), con lo que produce una superposición de focalizaciones o "punto[s] desde el que se contemplan los elementos" en el relato (Garrido Domínguez, 2007: 139): la externa del narrador y también la interna de la protagonista. En estos casos es difícil distinguir quién de los dos "filtra los acontecimientos" (Garrido Domínguez, 2007: 139), pues existe ambivalencia o, según Mike Bal, "focalización ambigua entre dos niveles" (2009: 119); es decir, en estas ocasiones no se puede distinguir claramente entre el focalizador interno (protagonista) o el externo (narrador). Este recurso permite una omnisciencia del narrador más natural y verosímil que la de la novela decimonónica tradicional, pues aquí es la misma Lucía la que selecciona los acontecimientos y narra su propia intimidad. Analizamos a continuación estos modos narrativos en Que nadie duerma.

\section{1. Narración ambigua}


Ya en el grupo oracional inicial de la narración - "al verse en el espejo, Lucía dijo: Esa gorda soy yo” (Millás, 2018: 9)- se aprecia un cambio de nivel por el que el narrador le cede el punto de vista o focalización a Lucía (introducido por "al verse”). O sea, el narrador en tercera persona maneja el relato y cuando desea cambiar de nivel (para dejar de ser él quien observa), elige "bisagras" o "señales de acoplamiento" (Bal, 2009: 19) -como "verse"- para indicarnos que es Lucía el focalizador. Como el cambio es frecuente, en algunos casos no está claro quién contempla los hechos, con lo que el narrador y el personaje se superponen; así, a continuación del texto citado, encontramos: "La niña se había ido a la cama intentando descifrar aquella contradicción. ¿Por qué parecía delgada si era gorda?” (Millás, 2018: 9). Pregunta, que podría ser adjudicada tanto al narrador como a la misma Lucía (después de examinado su cuerpo), es decir, nos encontramos con un caso de narración ambigua.

\section{2. Focalización de la protagonista (de su metamorfosis)}

Pero lo más sugerente para el lector es apreciar que la apariencia de pájaro de Lucía se aumenta a medida que ella se da cuenta que "había caído [...] en una trampa de personas cultas de la que ahora no sabía cómo escapar” (Millás, 2018: 169). En el momento en que ella descubre que Ricardo, Berta y Braulio habían recreado la historia de su vida en el teatro, Lucía se siente herida y, en ese mismo instante, se transforma totalmente en un pájaro (que llevará a cabo la atroz venganza). Ella focaliza su metamorfosis ya en su taxi de camino a su casa: "Mientras que esperaba que se pusiera verde, sintió en su cuerpo las primeras transformaciones físicas, pues le pareció que sus piernas, bajo los pantalones vaqueros, habían mutado en las patas de un ave" (166; las cursivas son mías). -El narrador cede la focalización a Lucía con los verbos "sintió y "le 
pareció". Estas “señales de acoplamiento" (Bal, 2009: 119) indican aquí el cambio de nivel del narrador externo a una focalización interna (Bal, 2009: 118)-. Igualmente, la protagonista continúa focalizándose como un ave cuando llega a su casa: "[Lucía] Fue a verse en el espejo, donde sus ojos contemplaron un cuerpo de mujer, pese a que la percepción interna era de un ave. Tenía un pico curvo, muy duro, capaz de desgarrar la pared del vientre de un hombre y sacarle las entrañas. Se vio haciéndolo sobre el cuerpo de Braulio Botas" (167; las cursivas son mías).

Asimismo, Lucía también es capaz de imaginarse (focalizarse) a sí misma en el futuro de la trama "se veía agitando las alas y las patas en el interior de una red invisible cuyos nudos dañaban su plumaje" (169; las cursivas son mías).

\section{3. Autoridad de verosimilitud por parte del narrador}

Pero lo que realmente da intensidad al relato -por llevar lo imaginario al mundo real (de la trama, claro) - es lo que llamo 'la autoridad de verosimilitud' que el narrador concede a la transformación de Lucía en pájaro, asumiendo así por su parte que ella es una mujer-pájaro. El narrador verificará que "Así, un día, en la segunda semana de marzo, despertó en medio de un charco de sudor frío y salió de entre las sábanas convertida en un águila poderosísima. Su cuerpo visible seguía siendo de mujer, pero su cuerpo fantasma era de ave. Y ninguno resultaba incompatible con el otro" (Millás, 2018: 170; las cursivas son mías). Desde este momento -solemnizado por "en la segunda semana de marzo"-, no solo Lucía se verá a sí misma como pájaro (un águila), sino que el narrador lo corroborará. Por esto, como anunciábamos, la trama de la obra se entreteje con la forma, pues el momento de la metamorfosis de la protagonista en pájaro se corresponde con un cambio en el modo narrativo. Ya el narrador no tiene que bajar de nivel, dándole la 
palabra a la protagonista mediante "bisagras" o "señales de acoplamiento", como "pensó" o "vio", para mostrar el aspecto de pájaro de Lucía; ahora el mismo narrador lo asume con toda su autoridad desde un primer nivel -“salió de entre las sábanas convertida en un águila” (170)-.

Con esto el lector experimenta un cambio en el juego narrativo; si en un principio solo debe "aceptar" las realidades focalizadas o imaginadas por Lucía - “con una pasión [de Lucía] capaz de borrar las fronteras entre lo real y lo imaginario" (77)-, ahora debe dar crédito a las del narrador, que autoriza con su relato la verosimilitud de la metamorfosis en ave de Lucía. El narrador relata: "Ahora mismo, por ejemplo, mientras sus pies de humana atienden a los pedales del automóvil y sus manos de cinco dedos sujetan el volante, sostiene sobre los hombros la cabeza de un águila, con su hermoso plumaje, sus ojos avisados, su pico de acero" (174; las cursivas son mías).

Esto que no quita que también se deslicen en el texto alternancias a la hora describir a la mujer pájaro; unas veces lo hará el narrador, y otras le cederá su punto de vista a la protagonista que será el focalizador - "Notó, eso sí, que tenía que recalcular las distancias respecto a sí misma” (170; las cursivas son mías)-. Pero siempre el lector deberá asumir el nuevo juego narrativo en el que la metamorfosis de Lucía es "real" (en la trama), porque el narrador lo ha confirmado.

Hemos mostrado que Millás transforma el mundo irreal de Sofía (sus pensamientos, fabulaciones y obsesiones) en reales en la trama novelesca. Esto lo lleva a cabo por medio de dos técnicas. En la primera, que aparece al principio del texto (hasta la página 170), las focalizaciones de la protagonista sobre su aspecto y sus fabulaciones crean expectativas en el lector de que su apariencia de pájaro es fruto de su imaginación (sería un intento de naturalizar por parte del narrador/autor la situación "no natural" de que 
Lucía es una mujer pájaro). La segunda, se lleva a cabo por medio de la autoridad del narrador -que hemos denominado 'autoridad de verosimilitud'-, pues este narrador confirma la violación de las convenciones miméticas de texto, es decir, que Lucía es un ave (Millás, 2018: 170); convenciones que son propias de la mayoría de las narraciones de paradigmas realistas.

Se concluye, pues, que el modo narrativo se acopla a la trama. Cuando la transformación de mujer en ave es total, el narrador lo verifica. Asimismo, el lector tiene que replantearse la aceptación de la verosimilitud de la trama. Ya no es Lucía quien imagina desde su punto de vista o focalización que es un ave, y quizá podría no serlo; ahora es el narrador quien lo confirma. Las reglas del juego narrativo han cambiado; Lucía es un ave "real" (en la trama novelesca), no imaginada por ella misma, que realiza una matanza completamente "real".

\section{4. Unnatural narrative o narración no natural}

Para la crítica actual anglosajona Que nadie duerma estaría considerada dentro de la tipología de las narrativas no naturales o "unnatural narratives" (Richardson, 2012: 95). Esta nueva tendencia narratológica -llamada Unnatural Narratology- pretende dar respuesta al estudio de narraciones postmodernas que no pueden ser estudiadas según las categorías estructuralistas. Como explica Culler, "Unnatural Narratology stresses the anti-mimetic character of a lot of fiction" (2018: 8). También para Brian Richardson, estas narrativas presentan sucesos que son imposibles en la realidad: "Unnatural narratives can be identified as those texts that violate mimetic conventions by providing wildly improbable or strikingly impossible events; they are narratives that are not simply non-realistic but antirealistic" (2012: 95). Y, muy acertadamente Jan Alber (2013) apunta que el criterio para seleccionar estos textos narra- 
tivos sería su imposibilidad para actualizar en el mundo real los sucesos o escenarios que se describen en ellos. ${ }^{10}$

Aunque, como hemos visto más arriba, esta narratología ("Unnatural Narratology") ha acotado su campo de estudio, aun no presenta una metodología de análisis aplicada. Por eso, hemos analizado Que nadie duerma de Millás desde el punto de vista de una narratología basada en los principios estructuralistas como la que presenta Mike Bal (2009). Creemos que este cuerpo teórico ha dado una respuesta válida ya que se ha mostrado las complejas relaciones internas entre sentido y forma que estructuran este objeto estético.

\section{Conclusiones}

Que nadie duerma de Juan José Millás es una novela que presenta a una mujer acribillada por la situación socioeconómica del siglo XXI, que recurre al amor como evasión y salvación. Incurre así en un estado de limerencia que desemboca en un fin trágico, provocado por su sed de venganza hacia las personas que se han mofado de ella.

He estudiado la configuración de este personaje femenino desde su complejidad psicológica, y cómo esta determina sus relaciones con el mundo en el que habita. He mostrado que uno de los recursos utilizados por Millás para construir a la protagonista es el encuentro traumático de lo individual y lo social (o entre la limerencia y la hiperculturalidad).

La mujer que se enamora a primera vista, que es burlada por su ser querido y su amiga, probablemente, es una 'historia' manosea-

${ }^{10}$ Según Alber: "The criterion for identifying unnaturalness is actualizability, which bears on the question of whether the represented scenario or event could exist in the real world or not" (2013, "Explication": 3). 
da (tanto en la vida real como en la ficción), pero lo sobrecogedor para el lector de esta novela es la fuerza casi sobrenatural que el autor confiere a la protagonista para satisfacer su venganza. Y esto lo consigue, como hemos seńalado, por medio de una estructuración de recursos literarios sabiamente manipulados: protagonista construida con rasgos del modelo psicológico del sujeto limerente, trama que refleja el ambiente hipercultural de la sociedad neoliberal y, finalmente, modos narrativos (narración ambigua y focalización) en consonancia con el sentido.

El narrador en el momento culmen y final de la obra asume el punto de vista de Lucía, dando verosimilitud (en la trama) con su autoridad al mundo imaginario y antirreal de la protagonista (que Lucía es una mujer-pájaro).

En esta novela emerge un sentimiento de venganza que traspasa las fronteras del género y de los tiempos, porque refleja el de cualquier corazón enamorado y, luego, herido injustamente. Por esto Que nadie duerma adquiere una dimensión universal que la convierte en un texto literario y objeto estético, seguramente apreciado por lectores y lectoras de todas las épocas.

\section{Referencias bibliográficas}

Alber, Jan, 2014, "Unnatural Narrative", en Hühn, Peter et al. (eds.), The living handbook of narratology, Hamburg University, Hamburgo. Disponible en: http://www.lhn.uni-hamburg.de/ article/unnatural-narrative (consultado: 22/XI/2019).

Bal, Mieke, 2009, Teoría de la narración: una introducción a la narratologia, Cátedra, Madrid.

Chessick, Richard D., 1992, "On falling in love and creativity", Journal of the American Academy of Psychoanalysis, vol. 20, núm. 
3, pp. 347-373. Disponible en: https:/guilfordjournals.com/ doi/abs/10.1521/jaap.1.1992.20.3.347

Contadini, Luigi, 2013, "Las novelas de la Transición de Juan José Millás: 'Cerbero son las sombras', 'Visión del ahogado', "El jardín vacío", Impossibilia, Revista de Estudios Literarios, núm. 5, pp. 32-46. Disponible en: http://digibug.ugr.es/handle/10481/41819

Culler, Jonathan, 2014, Breve introducción a la teoría literaria, Espasa, Barcelona.

, 2018, "La teoría crítica hoy", Theory now and again, Monográfico: Jonathan Culler, vol. 1, núm. 1, pp. 1-16.

Dorca, Toni, 1997, "Joven narrativa en la Espańa de los noventa: la generación X”, Revista de Estudios Hispánicos, vol. 31, núm. 2, pp. 309-24.

Earp, Brian D., et al., 2017, "Addicted to love: What is love addiction and when should it be treated?", Philosophy, Psychiatry \& Psychology: PPP, vol. 24, núm. 1, pp. 77-92. Disponible en: https://philpapers.org/rec/EARATL

Flora, Carlin, 2017, "Down with extremes. Health, well-being, and success rest on one principle: In all things moderation", Psychology Today, julio-agosto. Disponible en: https://www.psychologytoday.com/gb/magazine/archive

Garrido Domínguez, Antonio, 2007, El texto narrativo, Síntesis, Madrid.

Han, Byung-Chul, 2018a, Hiperculturalidad, Florencia Gaillour (trad.), Herder, Barcelona.

, 2018b, La expulsión de lo distinto, Florencia Gaillour (trad.), Herder, Barcelona.

Kafka, Franz, 2018, La metamorfosis, Alianza editorial, Madrid.

Millás, Juan José, 2018, Que nadie duerma, Alfaguara, Barcelona. 
, 2002, Dos mujeres en Praga, Espasa Calpe, Madrid.

Montejo Gurruchaga, Lucía, 2010, “La novela española actual desde la transición. Juan José Millás. Entrevista” [Audio], Canal Uned, 28 del 03. Disponible en: https://canal.uned.es/ video/5a6f40a5b1111f0a678b45b8

Richardson, Brian, 2012, "Unnatural narratology: Basic concepts and recent work", Diegesis, vol. 1, núm. 1, pp. 95-102. Disponible en: http://elpub.bib.uni-wuppertal.de/servlets/DerivateServlet/Derivate-3269/dej12010111.pdf

Tennov, Dorothy, 1979, Love and limerence: The experience of being in love, Stein and Day, Nueva York.

Wakin, Albert H. y Duyen B. Vo, 2008, "Love-variant: The WakinVo IDR model of limerence", Inter-Disciplinary-Net. 2nd Global Conference; Challenging Intimate Boundaries. Disponible en: https://digitalcommons.sacredheart.edu/psych_fac/131/

Willmott, Lynn y Evie Bentley, 2015, "Exploring the lived-Experience of limerence: A Journey toward authenticity", The Qualitative Report, vol. 20, núm. 1, pp. 20-38. Disponible en: https://nsuworks.nova.edu/tqr/vol20/iss1/2/ 